\title{
GESTÃO DEMOCRÁTICA E REGIMENTO ESCOLAR: UMA CONEXÃO NECESSÁRIA
}

\author{
Fernando da Costa Ribeiro ${ }^{1}$
}

RESUMO: Tendo em vista a dinamicidade e heterogeneidade nas formas de pensar e agir dos sujeitos no contexto da sociedade contemporânea, na qual a educação tem como demanda principal formar cidadãos críticos e participativos, se faz mister a construção e o cumprimento do Regimento Escolar como exercício pleno de uma gestão democrática que prima pela autonomia e pela participação conjunta dos atores escolares, a fim de nortear as ações administrativo-pedagógicas da instituição de acordo com suas especialidades, bem como assinalar os princípios de convivência entre os setores no cotidiano escolar. Sob esta ótica objetivou-se analisar a atuação da equipe gestora na efetividade do Regimento Escolar, bem como verificar o nível de participação na construção deste documento, e em que medida este documento é construído e (re)conhecido pelos atores da comunidade interna de algumas escolas no Amapá. A base teórica conceitual adotada ancorou-se nas idéias de Vianna (1986); Veiga (1995); Saviani (1997); Oliveira (1998) Andrade (2001); Demo (2002); Santos (2002); Libâneo (2004); Luck (2007) dentre outros. Optou-se pela metodologia de abordagem descritivo-qualitativa nos moldes da pesquisa de campo com procedimento de entrevista e questionário como instrumentos de coleta de dados, aplicados aos membros que compõem a Escola. Conclui-se que o Regimento das escolas pesquisadas foi construído de forma antidemocrática, como pacotes prontos que pretendem dar conta da realidade de todas as escolas já que na maioria das vezes é um instrumento único para todas as unidades, especialmente na esfera pública de ensino. Os atores escolares não participaram desta concepção implantada nas escolas, pouco se conhece sobre o documento e/ou questiona acerca de sua efetividade; o que exprime a ausência dos princípios da gestão democrática.

Palavras- Chave: Gestão Democrática. Autonomia. Regimento Escolar.

\section{INTRODUÇÃO}

Os processos de democratização dos sistemas de ensino e da instituição escolar propiciam um aprendizado muito significativo e amplia a vivência do exercício de

\footnotetext{
${ }^{I}$ Doutor (UAA/UNB), Mestre (UAA/UJAEN-ES), especialista em Educação (NAEA/UFPA). Pedagogo (UNIP) e Professor(UFRRJ).E-mail: ecofernando@uol.com.br.
} 
autonomia e tomadas de decisões. Este processo, no entanto, necessita ser discutido e construído no coletivo, sendo que ele não se efetiva somente pelas vias da normatização legal, mas é resultante, sobretudo, da concepção de gestão e de participação que os atores sociais envolvidos na educação querem de fato constituir, estando em sintonia com o contexto externo, visto que a escola não é uma ilha que se encontra isolada, mas é antes de tudo um lugar para se ampliar as relações com o mundo e com a vida (OLIVEIRA, 2005).

Pensar as políticas de gestão democrática para o ensino público implica numa tentativa de compreensão da escola e de seus processos, bem como a buscar a articulação do espaço escolar com as relações mais amplas do contexto social. A escola é o local onde podem ocorrer inúmeras contradições e, neste sentido, este meio deve ser promotor do diálogo, que leve ao respeito às diferenças e, garanta a liberdade de expressão e a vivência de processos de convivência mais humanizadores.

Então, para se refletir sobre a gestão democrática na escola brasileira, deve-se fazer uma análise das perspectivas atuais das políticas públicas em educação, a partir da Constituição Federal de 1988 e da nova Lei de Diretrizes e Bases da Educação (LDBEN 9.394/1996). Em meio a tantas determinações legais, procede-se à discussão sobre a gestão democrática da escola, que é favorável a uma maior participação dos agentes educacionais pais, alunos, professores e funcionários na construção da efetiva autonomia da escola. Discute-se também, sobre a gestão escolar e seu papel relevante frente aos novos desafios da educação.

Frente às inúmeras transformações que ocorrem atualmente na sociedade, a escola necessita repensar o seu papel. As mudanças que ocorrem na sociedade em larga escala são oriundas dos novos paradigmas do conhecimento e da revolução científica e tecnológica e da crescente exclusão social (VIEIRA, 2006). Os novos desafios da contemporaneidade remetem aos questionamentos que não é possível de serem ignorados: qual é o papel da escola hoje? Qual é o papel dos professores e como proceder na gestão desta escola? De modo geral, é possível perceber que a educação, na sociedade globalizada possui um valor 
significativo para o desenvolvimento social e para a conquista da cidadania e qualidade de vida.

A participação constitui-se numa das melhores maneiras de assegurar a gestão democrática da escola, possibilitando o envolvimento de toda a comunidade escolar na tomada de decisões e no funcionamento da organização educacional. De acordo com Luck (2007), através da participação consciente e crítica será efetivado o maior conhecimento dos objetivos e metas, da estrutura organizacional e das relações da escola com a comunidade.

O Regimento Escolar pode se tornar uma via de acesso para se alcançar uma boa qualidade da educação (no sentido literal da palavra - educar a ação), por meio da conscientização dos direitos e deveres de todos os membros da comunidade escolar, por se tratar de um corpo doutrinário e normativo de uma prática política (LIBÂNEO, 2004). O regimento visa amparar as instituições escolares, bem como o processo educativo como um todo, através dos princípios da democracia, da ética e da cidadania e tendo em vista a sua relevância para a prática política e cidadã da comunidade escolar, dentro e fora dos muros escolares.

A falta de informação sobre o Regimento Escolar e o não entendimento deste pela sua comunidade como diretriz técnica, pedagógica, administrativa e disciplinar das instituições de ensino, acaba por afastar a escola de um dos objetivos da educação contemporânea que é educar para a cidadania, formando cidadãos críticos e participativos da sociedade em que estão inseridos.

Esta pesquisa poderá subsidiar a práxis educativa e levar os sujeitos envolvidos a refletir sobre a importância de conhecer o seu Regimento para atuar sobre ele de maneira democrática, consciente e direta.

Os principais teóricos que embasam o trabalho são: Piletti (1988); Demo (1997); Veiga (1995); Saviani (1997); Oliveira (1997); Boas (2002); Vasconcelos (2002); Libâneo (2004); Cury (2005); entre outros. Estes autores trazem contribuições importantes, na medida em que nos embasam sobre os princípios de uma gestão democrática, bem como os 
conceitos do Regimento Escolar, sua construção e cumprimento nas instituições escolares, bem como na reflexão da organização das escolas municipais e o imperativo e papel da gestão na efetividade do Regimento Escolar.

A opção metodológica pauta-se na abordagem de natureza qualitativa e descritiva com lastro em revisão de literatura associada a visitas de campo, com procedimento de entrevistas e viés interpretativo aplicados na Secretaria de Educação e em 2 escolas do município, sendo uma da Zona Urbana e outra da Zona rural, visando analisar o grau de conhecimento e cumprimento do Regimento Escolar, bem como verificar o que é comum e singular em cada contexto.

\section{EDUCAÇÃO BRASILEIRA E A GESTÃO ESCOLAR DEMOCRÁTICA}

\section{I A EDUCAÇÃO BRASILEIRA DO TEXTO AO CONTEXTO}

A História da Educação no Brasil inicia-se no período colonial, quando começam as primeiras relações entre Estado e Educação, através dos jesuítas que chegaram em I549, chefiados pelo Padre Manoel da Nóbrega. Em 1759 houve a expulsão dos jesuítas (reformas pombalinas), passando a ser instituído o ensino laico e público, e os conteúdos baseiam-se nas Cartas Régias. Muitas mudanças ocorreram até que se chegasse à pedagogia dos dias de hoje. É a partir de 1930, início da Era Vargas, que surgem as reformas educacionais mais importantes (TEIXEIRA, 1976). A primeira LDB é promulgada em I946 (Lei no 4.024/6I), que instiga o desencadeamento de vários debates acerca do tema.

A Constituição Federal de 1988, promulgada após amplo movimento pela redemocratização do País, procurou introduzir inovações e compromissos, com destaque para a universalização do ensino fundamental e erradicação do analfabetismo. As novas políticas sociais pedem os seguintes sentidos: dar continuidade ao processo de desenvolvimento humano, compensar conjunturalmente os efeitos da revolução tecnológica e econômica e instrumentalizar a política econômica.

O Banco Mundial é o principal organismo internacional de financiamento de projetos de desenvolvimento na área educacional, possuindo um papel estratégico no 
reordenamento da ordem mundial ao ser o incentivador das políticas de ajuste estrutural dos países em desenvolvimento (VIEIRA, 2002).

A nova LDB, lei n o 9394/96, teve um início diferente da tradição de leis criadas para a educação no país, pois, desta vez, estabeleceu-se um grande debate na sociedade. Era um projeto de concepção socialista (SAVIANI, 1997), com um caráter progressista e democrático, que foi gerado com a participação de entidades da sociedade civil.

De acordo com Santos (2002) a gestão educacional, como função atípica e diferente de qualquer atividade depende da filosofia e da política educacional do país e da postura pedagógica assumida nas escolas. Se a concepção de Instituição Social parte do conceito do instituído e a educação como transmissora do passado, tende- se a reforçar o papel da escola como repassadora de valores e padrões. Partindo de uma concepção de Instituição Social inspirada na dialética do instituído.

O novo modelo de gestão educacional enfatiza que a liderança deve buscar intencionalmente influenciar os outros atores do processo educativo a usarem seu potencial, a realizarem tarefa e atingirem objetivos e metas maximizando o desenvolvimento organizacional e pessoal conjuntamente. Suas características principais deverão apontar para credibilidade, convicção, caráter, cuidado, coragem, compostura e competência.

\subsection{TIPOLOGIA DA GESTÃO ESCOLAR}

A participação na gestão da escola proporcionará um melhor conhecimento do funcionamento da escola e de todos os participantes proporcionando um contato permanente entre professor e aluno, o que leva ao conhecimento mútuo, atendendo as necessidades do aluno dos conteúdos ensinados pelos professores.

Neste sentido tem-se como tipologia da gestão escolar: a Gestão Democrática, Gestão Autocrática e Laissez-Faire.

A Gestão Democrática é uma ferramenta importante no processo ensino aprendizagem da democracia, onde a escola não tem um fim em si mesmo, mas está 
sempre prestando serviço também à comunidade que a mantém sendo que na escola tem que está a amplitude da sociedade. A gestão democrática deve está impregnada na atmosfera que se respira na escala através das informações, na divisão do trabalho, no estabelecimento do calendário escolar, na distribuição das aulas, no processo de elaboração de novos cursos, entre outros, contribuindo na capacitação dos recursos humanos para melhorar a qualidade de ensino. É uma administração colegiada, onde a educação é tarefa de todos; família, governo e sociedade precisam estar envolvidos, trabalhando coletivamente para atender às exigências do processo educacional (SANTOS, 2002).

A atuação do gestor será mais eficaz tendo consciência que precisa trabalhar em conjunto, pois não há administração satisfatória sem a participação de todos, onde ele impõe o menos possível e aceita a afetividade de um processo participativo, superando seus medos. Pois a participação não é o resultado automático espontâneo, mas de conquista diária que resulta no fortalecimento e responsabilidade dos indivíduos.

A gestão autocrática é o tipo de gestão centralizada na pessoa do líder onde o cuidado às considerações para com os sentimentos das pessoas que estão sobre o seu poder, não são levadas em conta. As técnicas usadas são consideradas unicamente ao ato de dar ordem, delegando às pessoas o que deve ser feito em cada momento, e de fiscalizar se as ordens estão sendo cumpridas. Essa gestão é um tanto rígida, onde o líder age de forma egoísta porque distribui as tarefas exigindo o cumprimento da parte sem pronunciar o próximo passo a seguir e quais objetivos serão alcançados. O líder não está preocupado com a opinião dos seus liderados importando-se somente com a sua posição, transformando o trabalho num ambiente de comando. Assim sendo o grupo submetido à gestão autocrática torna-se dependente em relação às atitudes do líder, pois em sua ausência não tomam iniciativa quanto ao término ou inicio de um trabalho (SANTOS, 2002).

Já a gestão Laissez-Faire caracteriza-se pela atitude passiva do gestor, que não apresenta postura crítica e está sempre confiando nas decisões individuais das pessoas, abstendo-se de dar sugestões. O gestor nesta ótica, não se envolve com as atividades de 
áreas de seus funcionários e exerce pequenas influências, conhecido como "deixa rolar", tendo, portanto, menor visibilidade por parte dos funcionários. É certo que um grupo precisa ver em seu líder uma postura de firmeza e clareza e a explicitação dos objetivos a serem alcançados. Pois quando parte do líder atitudes de incerteza e confusão, gera-se no grupo um descontentamento, impedindo o bom desenvolvimento de suas ações, já que não há uma participação mútua (SANTOS, 2002).

\subsection{A ORGANIZAÇÃO ESCOLAR E A GESTÃO DEMOCRÁTICA}

A escola é uma organização social em que diversas funções são realizadas em e por setores diferentes, em prol da qualidade do processo educativo, exigindo dos gestores uma postura proativa, planejamento adequado, atitudes dinâmicas e empreendedoras. A instituição escolar é o local onde podem ocorrer diversas contradições. Assim, o diálogo precisa ser exercitado como mecanismo de respeito às diferenças e garantia de liberdade de expressão, configurando-se numa vivência e convivência de contextos mais humanizadores.

A implementação de uma gestão democrática nas escolas traz novos desafios, pois implica na integração da escola na sociedade exigindo que se conheça e vivencie os problemas que a comunidade local enfrenta e, ao mesmo tempo, indica que deve haver um canal de comunicação que extrapole os muros escolares, que descentralize o poder de decisão, antes centrado nas mãos do diretor, socializando assim o poder coletivo na busca de se estabelecer metas e conseguir efetivá-las mediante as atividades planejadas.

Contudo, consolidar essas concepções teóricas à práxis educativa não se trata de tarefa fácil, pois participação efetiva, crítica e compromissada de todos implica em mudanças de padrões culturais, sobretudo da cultura assistencialista e clientelista, criando canais de diálogo, participação e transparência de forma que a população se torne um agente no desenvolvimento local, readequando a distribuição do poder da escola, por meio da institucionalização de mecanismos participativos como colegiado escolar, Projeto Político Pedagógico (PPP) e Regimento interno das escolas, por exemplo. 
Pensar numa gestão democrática implica considerar que a escola é feita de pessoas e que estas representam uma heterogeneidade em todos os seus aspectos físicos, cronológicos, cognitivos, culturais e socioeconômicos, o que aponta para a complexidade do processo de gestão democrática que não deve limitar-se às questões burocráticas e financeiras da escola nem invadir também os espaços dos demais membros da comunidade escolar. Ao contrário, cabe uma atuação dentro de dois parâmetros específicos - de onde parte o seu trabalho e para onde deve convergir. Implica ter claro que a sua finalidade é o pedagógico e que também o seu pedagógico é o fim, enquanto, os aspectos administrativos e financeiros são os meios para se buscar e garantir esse fim.

Diante dessa complexidade o gestor precisa estar atento ao seu ambiente de trabalho, às pessoas com quem trabalha e a quem lidera, bem como conhecer suas responsabilidades técnicas e administrativas, sua realidade, seus problemas, o seu quadro de funcionários, o aluno e se possível o contexto de onde cada um deles provém.

Neste sentido o Brasil passou a reconhecer a importância da participação popular na gestão e no controle social das políticas públicas na década de 1980 com o processo de luta em favor da redemocratização, a fim de garantir a universalização dos direitos sociais na promoção do exercício da cidadania. Assim a participação da sociedade na definição, cotização e avaliação dos sistemas de ensino do país em âmbito geral e de maneira particular (e não menos importante) das escolas torna-se cada vez mais necessária.

Uma das formas de articular a participação social na escola, dentro de um processo de gestão democrática, é a construção coletiva do PPP pelos membros da sua comunidade, configurando-se ainda em elemento de autonomia, que como contemplada na LDB 9394/96 é elemento inerente ao trabalho escolar que conjuntamente com a flexibilidade, a responsabilidade, o planejamento e a participação nessa construção apresentam-se como mecanismo transversal da realidade escolar.

Numa gestão democrática, o gestor precisará saber como trabalhar os conflitos e desencontros, deverá ter competência para buscar novas alternativas que atendam aos interesses da comunidade escolar, deverá compreender que a qualidade da escola dependerá 
da participação ativa de todos os membros, respeitando a individualidade de cada um e buscando nos conhecimentos individuais, novas fontes de enriquecer o trabalho coletivo.

Assim, ao se assumir o papel de gestor deve-se buscar necessariamente a articulação dos diferentes atores em torno de uma educação de qualidade, o que implica uma liderança democrática, capaz de interagir com todos os segmentos da comunidade escolar. A liderança do gestor requer uma formação pedagógica crítica e autônoma. Nesse sentido, o objetivo é construir uma verdadeira educação com sensibilidade e também com destreza para que se possa obter o máximo de contribuição e participação dos membros da comunidade.

\subsection{IMPERATIVO DE GESTÃO E SEU PAPEL NA EFETIVIDADE DO REGIMENTO ESCOLAR}

A gestão escolar, na maneira como é entendida na atualidade e prevista na legislação, implica uma ruptura histórica na prática administrativa que vem sendo implantada em nossas escolas ao longo da sua história, haja visto que tende a diferenciar

teoria e prática, concepção e execução, planejamento e efetivação, via ação conjunta, participativa, reflexiva e democrática.

Para Luck, (2007), gestão educacional corresponde ao processo de gerir a dinâmica do sistema de ensino como um todo e de coordenação das escolas em específico com as diretrizes e políticas educacionais e projetos pedagógicos das escolas compromissadas com os princípios da democracia e com métodos que organizem e criem condições para um ambiente educacional autônomo, de participação e compartilhamento, auto controle e transparência.

Coadunando com o autor, Andrade (2004, p.12,) coloca que “[...] é necessário que a direção supere o enfoque de administração e construa o de gestão, marcado por transformações, especialmente no que se refere a algumas concepções e aspectos básicos”, passando: 
- Da ótica fragmentada para a globalização em que todos participam da organização escolar, de forma interativa.

- Da limitação de responsabilidade pelos resultados para a sua expansão, promovendo a redefinição de responsabilidade, centradas no todo, independentemente das funções diferenciadas.

- Da ação episódica para o processo contínuo, por que a ação centrada em eventos é vazia de resultado, e a educação é um processo longo e contínuo.

- Da hierarquização e burocratização para a coordenação, pois a organização coletiva depende da construção individual, mas em ações coordenadas.

- Da ação individual para coletiva, porque o espírito de equipe, a participação e a democratização são grande desafio da gestão educacional.

Considerando que a mudança de paradigma da figura do administrador para o papel de gestor, é mais do que necessária, mas urgente e prevista legalmente, cabe-nos apresentar:

Tabela I - Mudanças de paradigma de administração para gestão

\begin{tabular}{|c|c|c|}
\hline Item & Administração & Gestão \\
\hline OI & $\begin{array}{l}\text { O direcionamento do trabalho consiste no } \\
\text { processo racional, exercido objetivamente de } \\
\text { fora pra dentro, de organização das } \\
\text { condições de trabalho e do funcionamento } \\
\text { das pessoas em um sistema ou unidade } \\
\text { social. }\end{array}$ & $\begin{array}{l}\text { O direcionamento do trabalho consiste no } \\
\text { processo intersubjetivo, exercido mediante } \\
\text { liderança, para a mobilização do talento } \\
\text { humano, coletivamente organizada para } \\
\text { melhor emprego de sua energia e de } \\
\text { organização de recursos, visando à realização } \\
\text { de objetivos sociais. }\end{array}$ \\
\hline 02 & $\begin{array}{l}\text { Ao administrador complete manter-se } \\
\text { objetiva, imparcial e distanciado da } \\
\text { produção, como condição para poder exercer } \\
\text { controle e garantir seus bons resultados. }\end{array}$ & $\begin{array}{l}\text { Ao gestor compete envolver-se nos processos } \\
\text { sob sua orientação, interagindo subjetivamente } \\
\text { com os demais participantes, como condição } \\
\text { pra coordenar e orientar seus processos e } \\
\text { alcançar melhores resultados. }\end{array}$ \\
\hline 03 & $\begin{array}{l}\text { Ação e prática que produzem bons } \\
\text { resultados não devem ser mudadas, a fim }\end{array}$ & $\begin{array}{l}\text { A alteração continua de ações e processos é } \\
\text { considerada como condição para }\end{array}$ \\
\hline
\end{tabular}




\begin{tabular}{|c|c|c|}
\hline Item & Administração & Gestão \\
\hline & que estes continuem sendo obtidos. & $\begin{array}{l}\text { desenvolvimento contínuo: a sua manutenção, } \\
\text { mesmo que favorável, leva à estagnação. }\end{array}$ \\
\hline 04 & $\begin{array}{l}\text { A autoridade do dirigente é comando, } \\
\text { controle e cobrança. }\end{array}$ & $\begin{array}{l}\text { A autoridade do dirigente é centrada e apoiada } \\
\text { em sua competência e capacidade de liderança. }\end{array}$ \\
\hline 05 & $\begin{array}{l}\text { O dirigente exerce ação de comando, } \\
\text { controle e cobrança. }\end{array}$ & $\begin{array}{l}\text { O dirigente exerce ação de orientação, } \\
\text { coordenação, mediação e acompanhamento. }\end{array}$ \\
\hline o6 & $\begin{array}{l}\text { A responsabilidade maior do dirigente é a } \\
\text { obtenção e garantia de recursos necessários } \\
\text { para o funcionamento perfeito da unidade. }\end{array}$ & $\begin{array}{l}\text { A responsabilidade maior do dirigente é a sua } \\
\text { liderança para a mobilização de processos } \\
\text { sociais necessários à promoção de resultados }\end{array}$ \\
\hline 07 & $\begin{array}{l}\text { O dirigente orienta suas ações pelo princípio } \\
\text { da centralização de competência e } \\
\text { especialização da tomada de decisões. }\end{array}$ & $\begin{array}{l}\text { O dirigente orienta suas ações pelo principio } \\
\text { da descentralização e tomada de decisão } \\
\text { compartilhada e participativa. }\end{array}$ \\
\hline o8 & $\begin{array}{l}\text { A responsabilidade funcional é definida a } \\
\text { partir de tarefas e funções }\end{array}$ & $\begin{array}{l}\text { A responsabilidade funcional é definida a } \\
\text { partir de objetivos e resultados esperados com } \\
\text { as ações. }\end{array}$ \\
\hline 09 & $\begin{array}{l}\text { Avaliação e análise de ação e de desempenho } \\
\text { são realizadas com foco em indivíduos e } \\
\text { situações especificas, consideradas } \\
\text { isoladamente, visando identificar problemas. }\end{array}$ & $\begin{array}{l}\text { Avaliação e análise de ação e de desempenho } \\
\text { são realizadas com foco em processos, em } \\
\text { interações diferentes componentes e em } \\
\text { pessoas coletivamente organizadas, todos } \\
\text { devidamente contextualizados, visando } \\
\text { identificar desafios. }\end{array}$ \\
\hline Io & $\begin{array}{l}\text { O importante é fazer mais, em caráter } \\
\text { cumulativo. }\end{array}$ & $\begin{array}{l}\text { O importante é fazer melhor em caráter } \\
\text { transformador. }\end{array}$ \\
\hline
\end{tabular}

Fonte: Luck, (2007 p. 105 apud SALES, 2008 p. 4-5)

Nesse contexto, há que se distinguir "Gestão Autocrática” que se dá pela imposição do líder pela subornação, pela rigidez e pela centralização do poder. Ele é quem dirige sozinho a Gestão Liberal, conhecida como laissez-faire, onde o líder concede a autonomia para que os colaboradores tomem as decisões por si mesmos, ele pouco ou nada se envolve, aceita tudo, sua participação na maioria das vezes é apenas para informar e "Gestão 
Democrática" onde o líder é o facilitador, um sujeito engajado com todo o fazer dos colaboradores e com o caminhar da instituição. O gestor evoca a participação em favor da escolha por parte de todos e dos passos que precisam ser dados em prol da construção da escola que desejam.

\section{O TRABALHO DA EQUIPE GESTORA NA ELABORAÇÃO DO REGIMENTO ESCOLAR E A EDUCAÇÃO NO BRASIL}

\section{I REGIMENTO ESCOLAR: ASPECTOS LEGAIS, CONCEITO E LÓGICA}

O Regimento Escolar é o documento legal de existência obrigatória na unidade escolar, no qual é normatizada sua organização administrativa, pedagógica e disciplinar, assim como as relações entre seus diversos segmentos constitutivos (os públicos interno e externo).

Com origem na Proposta Pedagógica, o Regimento Escolar (também chamado de Regimento Interno da escola) a ela se volta para conferir-lhe embasamento legal, incorporando no processo de sua elaboração os aspectos legais pertinentes e as inovações propostas para o sistema de ensino, assim como as decisões exclusivas da escola no que concerne a sua estrutura e funcionamento. (REVISTA ESCOLA ATIVA, 200I).

Toda organização deve possuir um conjunto de normas e regras que regulem a sua atividade, impondo limites, estabelecendo direitos e deveres. Isso funciona com o Estado (Constituição), com organizações diversas (Estatutos), com empresas (Contrato Social), e também, funciona com estabelecimentos escolares.

No caso de escolas, denomina-se REGIMENTO ESCOLAR o documento, discutido e aprovado pelos seus participantes e que reúne as "Normas Regimentais Básicas" descrevendo as regras de funcionamento da instituição e para a convivência das pessoas que nela atuam. E enquanto documento administrativo e normativo fundamenta-se nos propósitos, princípios e diretrizes definidos na proposta pedagógica da escola, na legislação geral do país e, especificamente, na legislação educacional (PORTAL CONTEÚdO ESCOLA, 2004). 
Contudo, alguns cuidados devem ser tomados no tocante à elaboração do Regimento Escolar. Por tratar-se de um texto legal, devem ser observadas as normas sobre elaboração e redação de atos normativos.

Assim a escola deve ter autonomia para elaborar a sua Proposta Pedagógica, Administrativa e de Gestão, na qual se insere o Regimento Escolar, é imprescindível que os atores envolvidos nesse processo busquem fundamentos teóricos que lhes possibilitem um entendimento significativo do referido documento e estejam atentos aos aspectos legais inerentes à sua constituição, que deve se dá coletivamente, culminando num texto claro e de fácil compreensão, no qual se estabeleçam as funções e particularidades de cada setor.

\subsection{ATUAÇÃO DOS GESTORES SOBRE A ASSERTIVIDADE DO REGIMENTO ESCOLAR}

O Gestor Escolar é a peça-chave da equipe gestora para o sucesso de qualquer escola. Há quem diga, inclusive, que a escola tem a cara do seu Gestor, pois a marca de sua administração fica evidenciada em todos os setores do espaço escolar.

Comprova-se, desse modo, que todo Gestor é responsável por criar condições adequadas de trabalho onde haja respeito e confiança, definindo e distribuindo tarefas, dando apoio aos que estão sob sua liderança, revendo e avaliando resultados, assegurando, assim, condições para o alcance dos objetivos estabelecidos coletivamente.

É importante que a Gestão Escolar atue em conjunto com a sua comunidade, ouvindo os seus anseios e discutindo acerca de suas expectativas, sendo moderadores da diversidade de idéias, sem, no entanto, abrir mão de suas obrigações legais. Escolas administradas com eficiência e liderança mantêm atmosfera e ambiente de trabalho tranqüilos e propícios à aprendizagem.

Para alguns autores, a Gestão Educacional é produto da ação humana e não pode ficar presa a paradigmas da Teoria da Administração empresarial, pois como organização social ela é dinâmica e lida com pessoas; por isso, tem suas especificidades e não pode ser 
reduzida a seu aspecto instituído. Isso significa que a escola pode ter autonomia, tanto na definição de seu projeto pedagógico, como na condução de seu destino, deixando de ser apenas subordinada ao sistema, mas tê-lo como parceiro e colaborador.

Cada escola tem autonomia para determinar a melhor alternativa de ação, a partir de um projeto político pedagógico próprio, sem esquecer, contudo que "autonomia" não significa "soberania", já que a escola faz parte de um sistema público estadual e como tal deve seguir suas diretrizes. Seu modelo próprio de ação (projeto político pedagógico) deve ser elaborado com base na realidade da comunidade local e isso deve ser feito coletivamente para que atenda aos anseios da comunidade escolar.

Neste contexto, espera-se que um diretor de escola seja articulador da proposta pedagógica da escola, e atente para o cumprimento do Regimento escolar, o que exige competência, conhecimento, experiência, habilidade de relacionamento, comunicabilidade, iniciativa, arrojo, dinamismo, criticidade, criatividade, capacidade para perceber acertos e erros, crenças e valores visando à concretização da proposta pedagógica escolar.

Portanto, a gestão de pessoas demanda um gestor/educador, preocupado com as necessidades do grupo, que abre espaços de reflexão, troca de experiências e estudo, visando um movimento contínuo de ação/reflexão.

Com tantas ações a realizar, o gestor precisa conceber, dar a conhecer e conduzir a comunidade escolar a cumprir o seu Regimento, buscando uma maior organização da Instituição e das relações de convivência, inseparáveis do processo educativo. Por isso, ele tem de planejar, delegar tarefas, consciente de que sozinho não conseguirá atingir todos os objetivos sociais da escola, por isso se faz necessário, a gestão participativa, onde haja abertura para a atuação de sujeitos coletivos, e estes se sintam compelidos a atuarem em prol de um objetivo comum.

O Regimento Escolar poderá efetivar-se plenamente na medida em que atender a realidade institucional e que a equipe gestora não só tenha conhecimento da sua importância, mas que seja capaz de promover mecanismos que incitem a reflexão e a prática sobre o Regimento, tendo em vista as funções delegadas a cada setor da Instituição, 
bem como os deveres aos mesmos pertencentes, já que gestão democrática pressupõe participação, diálogo e posicionamento crítico de todos.

\subsection{QUEM PARTICIPA DA CONSTRUÇÃO DO REGIMENTO ESCOLAR}

O Regimento Escolar deve ser atualizado em consonância com o Projeto Político Pedagógico (PPP) da escola, e contar com a participação de todos os seus membros na sua constituição, por tratar-se não apenas de uma ferramenta de controle e organização, mas, principalmente, de um instrumento de democratização das relações, uma vez que define os limites, os compromissos e as possibilidades de participação de cada segmento, de cada função e de cada indivíduo na definição dos rumos da educação desenvolvida na escola.

Noronha (2004) pontua que o regimento escolar deve ser elaborado por: a) Diretor Geral; b) Diretor Executivo; c) Diretor Educacional; d) Coordenador Pedagógico; e) Coordenador Educacional; f) Secretário Geral; g) Corpo Docente; h) Conselho de Classe; i) Biblioteca; J) Laboratórios e Outros Ambientes Especiais. Sendo que cada um tem a sua função:

O Diretor Geral é responsável pela parte técnico pedagógica, competindo-lhe a representação da Escola perante os órgãos públicos federais, estaduais e municipais e a comunidade. O diretor tem como tarefa representar a Escola durante as autoridades e repartições em todos os eventos onde a Escola deve comparecer, podendo delegar poderes quando não o proibir a Lei.

O Corpo Docente será constituído de pessoal habilitado para a função e cumprirá as atribuições inerentes à sua profissão, tendo a responsabilidade específica que lhe cabe na organização curricular, no Plano Escolar e na Proposta Pedagógica da Escola.

O Conselho de Classe será constituído do Diretor de Unidade, do Coordenador Pedagógico, do Coordenador Educacional, e de todos os professores que lecionam numa mesma turma. O Conselho de Classe reunir-se-á ordinariamente no final dos trimestres e do ano letivo, sob a presidência do Diretor da respectiva Unidade Escolar e, extraordinariamente, sempre que se fizer necessário. 


\section{${ }_{4}$ CONSIDERAÇÕES FINAIS}

O processo de luta em favor da redemocratização instaurado no Brasil nos anos 1980, onde se reconhece a importância da participação popular na gestão e no controle social das políticas públicas, bem como a Reforma do Aparelho Ideológico do Estado na década de 1990, acaba dando autonomia às instituições públicas de administração gerencial, através do ajuste fiscal, da privatização e da publicização a tomarem decisões que politicamente lhes são competentes de forma pré-estabelecida. Assim, a educação e a necessária democratização do ensino público, resultantes das inúmeras transformações políticas, culturais, e sócio-econômicas, passam a figurar freqüentemente as pautas de debates sobre a educação que vigora no país desde os primórdios, caracterizada como educação catequética e elitista, passando pelo contexto repressor da ditadura militar que alienava e inculcava paradigmas postulados pela e em favor da elite dominante.

Os ideais de gestão democrática da atualidade, amparados pela LDB 9394/96, atribuem às instituições escolares autonomia administrativa, pedagógica, financeira e de gestão, implicando numa ruptura histórica na forma de gerir a escola pública.

Nesse contexto, a elaboração e aplicação do Regimento Escolar pela equipe gestora e sua comunidade, como um instrumento legal que norteie as ações inerentes ao processo educativo é de suma relevância para as relações estabelecidas no cotidiano escolar dentro e fora dos seus muros.

As pesquisas realizadas nos proporcionaram o entendimento de que a gestão educacional brasileira não pode mais ser concebida e/ou praticada de maneira autocrática, centralizando-se o poder das tomadas de decisão nas mãos do gestor e nem como liberal, deixando acontecer aleatoriamente, mas de forma essencialmente democrática, conduzida pelos princípios da ética, da autonomia, da participação coletiva e do diálogo, num ambiente em que a motivação esteja atrelada às relações intra e interpessoais indissociáveis do contexto escolar.

Nesta perspectiva, cabe ao gestor atuar comprometido pessoal e profissionalmente com o ensino que a escola almeja promover, colocando o seu fazer administrativo a serviço 
do fazer pedagógico, para que a participação de todos os setores da instituição aconteça mediante a criação de um clima organizacional acolhedor e democrático.

No contato direto com as comunidades escolares, concluímos que infelizmente, as escolas não conhecem o seu Regimento e assim sendo não podem atuar sobre ele, confirmando nossas hipóteses.

O Regimento Escolar precisa ser compreendido como o documento que expressa a filosofia da escola e especifica as condutas e procedimentos a serem adotados pela comunidade no seu dia a dia, configurando-se no exercício da autonomia plena de cada instituição, que deve estar inserido no PPP, mas não deve ser confundido como o próprio.

Assim como o PPP, o Regimento Escolar necessita ser construído coletivamente, orientado por princípios como o conhecimento efetivo da realidade escolar, da comunidade na qual se insere e para qual existe; no respeito à diversidade individual e cultural; na legitimação dos diretos inerentes à pessoa humana; devendo ainda atender aos requisitos legais para elaboração e redação de atos normativos. $O$ regimento deve apresentar um texto claro, de fácil entendimento para a comunidade assistida, abarcando em suas disposições a proposta pedagógica da escola assinalando inclusive, o modelo de gestão, bem como indicar as situações em que cada setor da instituição deve buscar o documento para solucionar os problemas que se lhes apresentarem no cotidiano escolar.

Em derradeiro, é oportuno um convite a todos a quem pertence o direito à educação a "guerrearem" conosco, munidos do desejo sincero de construir uma sociedade igualitária em que todos não tenham direito a ter direito somente, mas que os tenham respeitados, valorizados e efetivados na atuação cidadã conjunta que deve começar em nossas escolas (e porque não dizer, a partir da construção e legitimidade do regimento escolar).

Com o mesmo vigor o gestor precisa lutar pela qualidade do ensino, em favor de uma educação libertadora como propõe Paulo Freire em livro intitulado "Pedagogia da Autonomia". Precisa criar condições junto à comunidade assistida de implementar uma gestão democrática e integradora, na qual o Regimento Escolar deve constar como um 


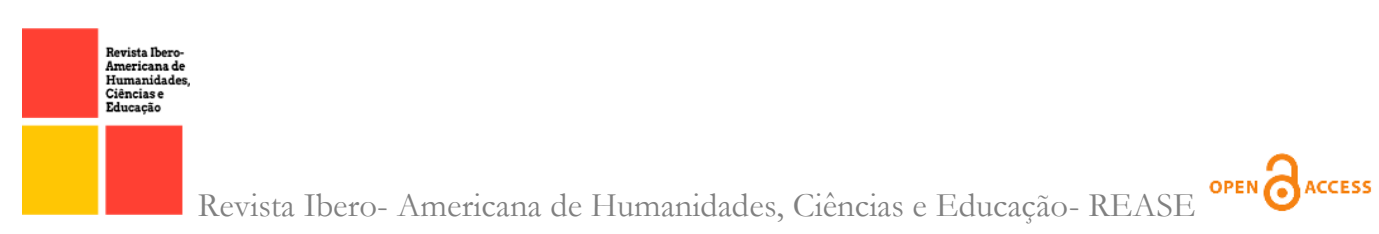

instrumento que aponte para o exercício cidadão de criticar, refletir e participar conjuntamente das ações vivenciadas no âmbito escolar.

Esse desejo de sociedade igualitária deve perpassar todos os setores da vida humana, para que nossos filhos, os filhos dos nossos filhos e seus descendentes possam vivenciar na escola e fora dela, glória e paz de forma onipresente. Alie-se ao nosso exército você também!

\section{REFERÊNCIAS}

ARANHA, Maria Lúcia de Arruda. Filosofia da Educação. 2ª Ed. rev. e ampl. São Paulo: Moderna, 1996.

ARANHA, Maria Lúcia de Arruda. História da educação. São Paulo: Moderna, I989.

BOAS, B.M.F.V. O projeto político- pedagógico e a avaliação. In Veiga,I.P.A. e RESENDE, MG . ( Orgs ). Escola: Espaço do projeto político-pedagógico, Campinas, Sp: Papirus, 2002.

CORAGGIO, José Luis. Propostas do Banco Mundial para a educação: sentido oculto ou problemas de concepção? In: DE TOMMASI, L: WARDE, S. (orgs). O Banco Mundial e as políticas educacionais. São Paulo: Cortez, 1996.

CURY, Carlos R. Jamil. Lei de Diretrizes e Bases e perspectiva da educação nacional. Revista Brasileira de Educação , no 8, p. 72-85, 1998.

DELUIZ, Neise. O modelo das competências profissionais no mundo do trabalho e na educação: implicações para o currículo. Boletim Técnico do SENAC, v. 27, n 3 , set./dez., 2001.

DEMO, Pedro. A Nova LDB: Ranços e Avanços. Campinas: Papirus, 1997.

DEMO, Pedro. Gestão Escolar e Formação de Gestores. Em Aberto, v. 19, número 75, p. I48-I5o, julho de 2002. Brasília, DF. 
FREIRE, Paulo. Pedagogia da Autonomia. Saberes necessários à Prática Educativa. São Paulo: Paz e Terra, 1996.

LIBÂNEO, J.C. Organização e Gestão da Escola: Teoria e Prática, 5. ed. Goiânia,

LUCK, Heloísa. Gestão educacional: uma questão paradigmática. Petrópolis, RJ.Vozes,2007.

NEVES, Lúcia Maria W. (Coord). Política educacional nos anos 90: determinantes e propostas. Recife: Ed. Universitária da UFPE, 1995.

OLIVEIRA, M. A. M. (org) Gestão Educacional - Novos Olhares Novas abordagens, Petrópolis, RJ:Vozes, 2005

PILETTI, Claudino; PILETTI, Nelson. Filosofia e História da Educação. $7^{\underline{a}}$ Ed. São Paulo: Ática, 1988.

RIOS, Terezinha Azeredo. Compreender e ensinar: por uma docência da melhor qualidade - 2a. ed. - São Paulo: Cortez, 200ı.

ROMANELLI, Otaíza de Oliveira História da Educação no Brasil Petrópolis, Vozes, 2002.

SANTOS, Clóvis Roberto dos. O Gestor Educacional de uma Escola em Mudança. Pioneira, Thomson Learning, São Paulo, 2002.

SAVIANI, Demerval. A nova LDB: limites e perspectivas. In: A nova lei da educação: trajetória, limites e perspectivas Campinas: Autores Associados, 3a ed. (Coleção Educação Contemporânea) 1997.

TEIXEIRA, Anísio. Educação no Brasil. São Paulo: Ed. Nacional, 1976.

VEIGA, Ilma Passos, Projeto Político da Escola: uma construção coletiva. Projeto Político Pedagógico da Escola: uma construção possível/ Ilma P. A. Veiga (org.). Campinas, SP: Papirus, I995. 